\title{
A Study on the Interaction between Chinese Traditional Sports Health Culture and National Health*
}

\author{
Lichun Wei \\ School of Physical Education \\ Hechi University \\ Yizhou, China 546300
}

\begin{abstract}
Traditional sports health culture is an important branch of Chinese medicine theory, and it is also an important part of traditional culture. To explore the effects of traditional sports health culture on the health of the whole people is of great significance to guide people to take scientific and reasonable health path. This paper uses the method of literature and logic analysis to study the research on the Chinese traditional sports health culture and national health. The results show that the main source of traditional Chinese sports culture is the activities of human health, and the second main source is the ancient witch and other mysterious things. The traditional sports health culture mainly concentrates on the fitness and education, etc. It mainly applies to training the crowd. The ways of sports have a very high degree of fit with the concepts of health. The traditional sports health culture uses all kinds of ways to promote the national health. It mainly reflects that the traditional sports health culture enters into the classroom and life. And the government departments strengthen the construction of sports infrastructures and ideological and ethical standards. It advocates the guiding ideology of "people-oriented, health first, lifelong sports ".
\end{abstract}

Keywords—sports health culture; national health; interactive research

\section{INTRODUCTION}

With the rapid development of China's economy, the social competition is becoming more and fiercer, and the environmental pollution is becoming more and more serious. Especially in order to speed up the urbanization and socialization, the governments of many places develop the economy at the expense of the environment. And any government who neglects this point will pay the big price. And in this process, they have the same idea that put the development in the first position and curb environmental pollution. In this situation, the environment of the entire global is threatened. Therefore, the health problems have

*Fund Project: (1) In 2016, the Research on Humanities and Social Science, the Ministry of Education, Project Number: 16XJA890002. (2) In 2016, the western project of national philosophy and social science fund project number: 16XTY002. (3) In 2016, a special project for construction of the master degree program of Hechi University. Project Number: 2016LG011. (4) The construction of key subjects of Hechi University: physical education and training. become a serious challenge for the human. With the improvement of people's awareness, people gradually realize the importance of health. In the meantime, the President, $\mathrm{Xi}$ Jinping puts forward the important speech of "To make efforts to promote the national health in all-round, full-cycle ways" in the National Sanitation and Health Conference. With the proposal of "healthy China", people are increasingly concerned about health issues, and health issues have become a hot topic. In this sense, people urge to realize the health knowledge. So, the return of traditional sports health culture is a necessary topic.

\section{A BRIEF INTRODUCTION TO CHINESE TRADITIONAL SPORTS CULTURE}

Chinese health culture has a long history. From the preQin era to today, Chinese traditional sports health culture continues to develop. From the unearthed oracle-bone inscriptions, it found that there are many things related to the concept of health culture in their daily lives. And it also showed the long history of traditional Chinese sports culture. The original of traditional Chinese sports culture is mythological.

\section{A. The Main Sources Are Ancient Human Health Activities}

According to the historical records, Yin Kang is a leader of a tribe who lived before the three sovereigns and five emperors Shen Nong times. And he creates a "dance" with the actual needs of production and life. The purpose of the dance is to make propaganda. The dance can mediate the physiological state and mental state. To a certain degree, this dance stretches the bones of people bones stretch, and ease the spirits of people. In this way, Yin Kang's "dance" is similar to the guided operations.

\section{B. The Secondary Sources Are the Ancient Witchcraft and Supernatural Trickery}

In ancient times, it prevailed to worship nature and evils. In order to achieve the communication with the God, the wizard appeared. And in order to show the communication with the gods, the shaman was good at singing and dancing. They believed that it could please the evils. In addition, 
people in the ancient society generally believed that the diseases were caused by hungry ghosts. And in this case, it needed to use witchcraft to get rid of witchcraft. In ancient China, there are lot of longevity, immortality and other myths and legends. The beautiful fairylands fully mobilize people's imagination. And the pursuit of longevity has become the aspirations of people. The supernatural trickeries play an important role in the development of health preservation. However, the supernatural trickery started in later time. It could not be the earliest source of traditional Chinese health like health care activities and witchcraft.

\section{THE EFFECTS OF CHINESE TRADITIONAL SPORTS Culture ON HeAlth}

Since the ancient times, health problems have always been a topic of discussion for the mankind. The pursuit of health has become a part of people's daily life. Xi Jinping, the president made an important speech on the health of people in National Sanitation and Health Conference in August 22, 2016. He put forward that to make efforts to promote the national health in all-round, full-cycle ways. And this speech caused a strong reaction in experts and scholars, professional visitors and the broad masses of the people. Experts and scholars pointed out that the all-round and full-cycle protection of people's health reflects the "people-oriented" concept of governance. It provides a strong foundation to protect the development of new China. So the values of the traditional sports health culture can be divided into the following two aspects.

\section{A. The Fitness Role of Chinese Traditional Sports Health Culture on the Health}

In the narrow sense, health culture refers to the thoughtform of health. And in the broad sense, the health culture is the development of the civilization of human society. It has a long history of the development. With the time going, the health culture has influenced by other different cultures. And its inherent contents and meanings were replaced by new contents and marks of the era. For example, health-care qigong, eight trigrams boxing, Tai Chi, and other traditional sports are widely praised in today's society. And you can see these exercises involved in people's daily life. And it is a good embodiment in the process of promoting the national health.

1) To be full of energy, and self-cultivation are the essence of health: The self-cultivation is a relatively large topic. Based on the rules of the development of people's lives, it keeps the cultivation of temperament through various methods. In the final, it would enhance the physical fitness. And it also improves their ability to adapt to the external environment and immunity. And then, their lives would reach the best state. The Chinese traditional sports always advocate the association of activity and inertia internally and externally. Through various movements and postures, people can get exercise. And the souls are purified. Also, it is conducive to release the pressure. They should adjust the psychology and maintain the mental health. In the end, it would achieve the physical and mental harmony.

2) The regular life is good for health: The knowledge on the Chinese traditional sports health culture theory is rich. However, it must return to the details of life. Then, it should throughout people's life. With doing like this, the health culture is of living. People's life can't be separated from the basic necessities and other things. These things have direct impacts on health. And they also affect the health. A regular lifestyle is helpful for us to live in a healthy state. And a regular life also provides us the normal life and work. If we have a regular life, our daily life is happy.

3) To be optimistic and open-minded. is a way of keeping good health: To be optimistic and open-minded is very important for a person in daily life. It can help you to maintain a good psychology in the life when you meet a problem. If you have a good psychology, you would not use the negative attitude to face the world when you deal with those troubles. And it can help you have a good physique, which is the essence of the traditional sports health. Attitude determines the behaviors. Behaviors determine the habits. Habits determine the health, and health determines the fate. If you want to control your own destinies, you must correct your own attitudes, and do anything following your own hearts. When you have healthy bodies and good attitudes, your life will be quality. And it will not affect your health because of your own ideology problems, which is also the essence of Chinese traditional health.

4) To control emotions, and keep healthy: All of us have their own emotions. When we face different things, we would have different emotions. When a person learned to control his emotions, then his physical and mental health will certainly has big changes in quality. As we know, when we encountered difficulties in life, it would be negative. And these negative emotions have negative effects on our health. It will affect our feelings and quality of life. For these negative emotions, the traditional sports health culture plays a guiding role in the concept of the fitness. The association of activity and inertia, self-cultivation and other contents of the traditional sports health culture have played a guiding role in controlling the emotions. Usually, the persons who blame themselves rather than others easily get happiness. And the persons who blame others rather than themselves easily get anger. So, all of us should improve the self-cultivation. With that, to realize the traditional sports health culture and to control own emotions are good to health.

\section{B. The Education Value of Chinese Traditional Sports Health Culture on the National Health}

Chinese traditional sports health culture involves a very rich cultural knowledge. Today, the development of society is very fast. People's pace of life is also fast. With the pressures of life and work, people can't live in their dreamy life scenes. The education values of traditional sports health on people's health become more and more important. 
1) To change the health concept, and improve the quality of life: With the rapid development of China's economy in recent years, people's life is getting faster and faster. And the life pressure is growing. In order to adapt to the development of the times, the so-called "sub-health" appears in our daily life. Therefore, to improve the quality of life has become a topic. And the traditional sports health culture focus on the internal and external thinking. The socalled "go to practice, practice outside the bones skin" to guide the current people's life.

2) To prevent the disease, and reduce the burden on the family: In the traditional health, it always includes the concepts of preventing the disease. It also shows that the world's good recipes should be to maintain a good state of the human body and take preventive measures. In order to maintain the health of the body, we must ensure that the body can resist both internal and external interference, which determines the prevention of sports health culture.

Traditional sports health is very suitable for the old men. To exercise the body is simple and flexible. And the forms of the exercise are various. It makes people feel relatively comfortable. And appropriate exercise can be a good prevention of disease. From this point of view, the traditional sports health is helpful to strengthen self-regulation. And it is helpful to improve immunity and other items. It plays an important role in reducing the burden on the family.

\section{THE CONSISTENCY BETWEEN CHINESE TRADITIONAL SPORTS HEAlTH CUlture AND National HEAlth}

Sports are the physical activities with consciousness to achieve a certain purpose. The traditional Chinese sports health is a fitness movement with the Chinese characteristics. It is the association of activity and inertia. And it also pays attention to its own harmony. It is physical activities with consciousness to achieve the self-cultivation. Traditional sports health is affected by the history in different periods. And it is the sports with the national characteristics, cultural heritage. And it handed down from generation to generation.

\section{A. To Fit the Crowd}

The goal of the national fitness is to improve the quality and the health of people. With young people and children as the focus, it advocates the concept of "to exercise one hour a day, and have the healthy life". The youth is strong, and the country is strong. The development of a nation needs the healthy development of young people. And the national fitness is the sports activities for ordinary people. And it also pays much attention to the sports activities of the young people. If the young people's health is not good, and physical and mental development is in deformity, it can't build the country with such national qualities. As we all know, the President, Xi Jinping puts forward the "Chinese Dream" in many occasions. In order to achieve this dream, it needs the young people to have a better physique and mentality. Therefore, people who participate in the national fitness are mainly young and middle-aged. And for the elderly, the national fitness needs to pay more attention to fitness needs of the crowd in this stage.

\section{B. To Fit the Means of Sports}

In the national fitness, people participate in various sports activities of the project. However, some sports needs some exercise skills, physical fitness and sports equipment and so on. For example, the football requires the high skills and the playground. In this case, the sports requires too much for the elderly. It is not suitable for the old men to play the football.

The concept of the traditional Chinese sports is the association of activity and inertia and the combination of yin and yang. For the old men, it is a concept of high-fit movement such as Tai Chi and other sports in martial arts. And this is a very good proof. Some of the fitness ideas and methods of the traditional sports are highly fitted in the activities of the middle and old people.

\section{To Fit the Health Concept}

Due to the rapid development of China's competitive sports, people's first impression on the participation in sports is to get a better score. Some people think that it needn't to participate in the sports activities. They think that to maintain a healthy mind is good for normal life. Obviously, it is a misunderstanding of this fitness concept. And for the competitive sports, it aims to get better results. However, the national fitness is to enhance physical fitness, and improve the national health. In the final, people will establish "health first, life-long sports" as a guiding concept. The traditional sports requires that each of us to participating in sports to maintain a calm state, and to establish "to exercise one hour a day" as the good idea. This concept of health is consistent with the concept of national fitness.

\section{Chinese Traditional Sports Health Culture PROMOTES THE MEANS OF NATIONAL HEALTH}

Today, the national health has been a hot topic. With the rapid development of the economy, people's pace of life is accelerating. And people's attention to health problems is not enough. In order to show themselves in life and work, it should strengthen the propaganda of the traditional Chinese sports health culture and other measures. It is a kind of ideological guidance and theoretical explanation of national health.

\section{A. To Strengthen the Promotion of Traditional Sports Health Culture, and Enter into the Classroom and People's Living}

"Tradition" may be relatively unfamiliar in today's society. In contemporary, the young people's understanding of the traditional culture is very limited. And the young people pay more attention to the popular things in today's society. The young people have little contacts with the essence of traditional culture. They may not have little understanding on the knowledge of the traditional sports culture. So what should we do in this case? It should let the traditional sports health culture enter into our teaching class. It should set up courses from compulsory education to higher education. And it also should be documented in the textbook. It should be in our examination range. And it is a strong 
force to promote the sports health, but also to provide a theoretical basis for the development of national health.

\section{B. To Strengthen the Construction of Sports Infrastructure, Especially Grass-roots Sports Infrastructure}

At present, China has a large population, a large gap in economic development and a large rural population. National health should not be the health of a few people. In order to achieve the national health, it must have the reform from the highest organizations down to the grass roots. Especially, it must provide the targeted help to the less developed areas. The requirements of sports fitness on the venues and equipment are still quite high. In this stage, the reality is that sports infrastructure in some rural areas is seriously inadequate. The project of the sports fitness that people participate in is mainly focused on running. And the development of the national health should be divided into many concepts. It can promote the equipment and playground in contents and values. Therefore, the government should increase the investment in sports and cultural undertakings. From the most basic aspects, so that people can get the basic guarantee in the national health.

\section{The Innovation of Traditional Sports Health Culture Content Make It Close to Life and Reality}

The innovation is the origin and driving force of cultural development. The development of culture needs to put forth new things, and to reform. It should constantly make the innovation of the traditional sports health culture. Combined with the current status of our national sports development, the traditional sports health culture is a theoretical basis. And it also has a strong guiding significance in our real life. It can turn the theoretical basis into a simple teaching method, so that ordinary people can learn how to live in a healthy life. And then, the traditional sports health culture would enter into people's lives. Then, it would improve the national health.

\section{CONCLUSION}

The current development of the national economy is fast. And people's pace of life is faster and faster. The health problems are a common problem for us to face. The state should increase the cultural propaganda. With the national credibility, it can promote the content and advantages of traditional sports health culture in television, newspapers and other media. The government should increase financial investment, and strengthen the sports infrastructure. And then, the sports would go into the people's lives from the city to the countryside from the developed areas to the backward areas. Then, it may achieve the national health. The innovation of traditional sports health culture content makes it close to the life and reality. At the same time, each of us should also develop good living habits, and establish lifelong sports awareness. It should adhere to "exercise one hour a day, health work for 50 years, enjoy the happy life". And our lives will be full of fun.

\section{REFERENCES}

[1] Liu Zhonghua. Chinese Health Culture and Modern Significance [J] Journal of Education College in Jilin Province: Academic Edition, 2011 (1): 14-15.

[2] Kang Jun, Chen Shaoqing. Alienation of Health Culture and the Extemporization of Sports Values [J]. Sports and Science, 2011,32 (5): 73-75.

[3] Yan Yi. Research on the New Classification Standard and Evaluation Index System of Minority Traditional Sports in China [J]. Journal of Capital Institute of Physical Education, 2015 (1): 65-69,74.

[4] Bai Jinxiang. The Value and Method of Minority Traditional Sports Project and Its Cultural Cataloging [J]. Journal of Physical Education, 2008 (9): 97-100

[5] Shu Yan Kai, Liu Shaoying. Classification and Protection of Traditional Sports in Hunan Ethnic Minority Areas [J]. Journal of Jishou University: Natural Science Edition, 2009 (2): 104-107.

[6] Zheng Daming. The Development and Application of the Traditiona Sports Project of Northeast Minorities in College Physical Education Teaching [J]. Education Exploration, 2011 (4): 27-28.

[7] Xu Baichuan, Li Jun, Qiao Fuxi. A New Study on the Origin and Development of Traditional Sports in China [J]. Journal of Liaocheng University: Natural Science Edition, 2003 (1): 72-74.

[8] Kang Deqiang. Research on the Traditional Sports Health Culture Philosophy [D]. Shanghai Institute of Physical Education, 2010 (1): 54-56.

[9] Wu Jingmei. A Comparative Study on Sports and Health in China and the West [J]. Journal of Shanghai Physical Education Institute, 2004 (6): 79-81

[10] Li Xiaolan, Tian Haiyan, Jia Junjie. Research on the traditional sports health concept of physical and mental health training [J]. Journal of Beijing Sport University, 2011 (8): 69-70,77.

[11] Hu Xiaofei. Research on the enjoyment of the traditional sports health training process [J]. Journal of Beijing Sport University, 2007,30 (10): 1336-1338. 